\title{
TIPONG TAWAR DALAM RITUAL PERTANIAN DAYAK PASER: SEBUAH BENTUK DAN STRUKTUR
}

\author{
Rika Istianingrum, Retnowaty \\ Universitas Balikpapan \\ riekaistianingrum@gmail.com
}

\section{ABSTRAK}

\section{ABSTRACT}

Tipong Tawar merupakan sebuah mantra yang digunakan dalam ritual-ritual adat suku Dayak Paser, Kalimantan Timur. Tipong Tawar merupakan mantra yang memiliki media berupa tepung berwarna putih dan tidak berasa yang disebut dengan tawar. Tipong Tawar sering disampaikan oleh seorang Balian (dukun/pawang) dalam ritual adat. Salah satu ritual adat tersebut adalah ritual dalam pertanian. Tujuan penelitian ini adalah mendeskripsikan bentuk dan struktur teks mantra Tipong Tawar dalam ritual pertanian Dayak Paser, Desa Baras Jiring, Kecamatan Muara Komam, Kabupaten Paser Kalimantan Timur. Jenis penelitian yang digunakan dalam penelitian ini adalah kualitatif. Menggunakan metode deskriptif serta pendekatan etnografi. Teknik pengumpulan data dilakukan melalui proses wawancara, perekaman, dan pencatatan. Hasil temuan menunjukkan bahwa bentuk dan struktur teks mantra Tipong Tawar merupakan struktur puisi karena mantra juga merupakan puisi lama dalam genre sastra. Adapun bentuk dan struktur teks mantra Tipong Tawar meliputi; tema, formula bunyi (rima dan irama), bait, baris, dan diksi. Dapat disimpulkan bahwa terkait dengan struktur pada teks mantra Tipong Tawar berdasarkan pada tema, rima, irama, bait, baris, dan diksi memang berbeda dengan struktur pada puisi pada umumnya, terutama pada diksi sebuah teks mantra. Karena diksi pada teks mantra menggunakan bahasa daerah yang tidak semua arti dalam bahasa Indonesia tidak dapat dimaknai secara harafiah. Hal ini yang membedakan mengenai diksi teks mantra dan diksi puisi pada umumnya.

Kata kunci: Tipong Tawar, mantra, Dayak Paser, bentuk, struktur

Tipong Tawar is a mantra used in customary rituals of the Dayak tribe of Paser, East Kalimantan. Tipong Tawar is a mantra that has media in the form of white flour and tasteless which is called tawar. Tipong Tawar is often delivered by a Balian (shaman / handler) in a customary ritual. One of the customary rituals is ritual in agriculture. The purpose of this research is to describe the form and structure of the text of the Tipong Tawar mantra in the Dayak agriculture ritual of Paser, Baras Jiring Village, Muara Komam Subdistrict, Paser Regency East Kalimantan. The type of research used in this study was qualitative, using descriptive method and ethnographic approach. Data collection techniques were done through interviewing, recording, and recording process. The 
findings show that the form and structure of the text of the Tipong Tawar mantra is a poetic structure because the mantra is also an old poem in the literary genre. The form and structure of Tipong Tawar mantra text include; themes, sound formulas (rhymes and rhythms), verses, lines, and diction. It can be concluded that related to the structure of the text of the Tipong Tawar mantra based on themes, rhymes, rhythms, verses, lines, and dictions are in contrast to the structure of poetry in general, especially in the diction of a mantra text. Due to the diction in the text of the mantra, using the local language that not all the meanings in the Indonesian language cannot be interpreted literally. This distinguishes the dictionary text of the mantra and the diction of poetry in general.

Keywords: Tipong Tawar, mantra, Dayak Paser, form, structure

PENDAHULUAN merefleksikan karakter masyarakat pendukung tradisi tersebut. Tradisi lisan dalam kehidupan manusia terbukti pemanfaatannya secara turun temurun dalam sebuah generasi manusia untuk menata kehidupan sosial budaya masyarakat tersebut.

Tradisi lisan tidak sekedar mencerminkan kehidupan budaya suatu kelompok masyarakat, penggalian nilai-nilai moral dalam tradsi lisan membawa fungsi sebagai pengendali perilaku manusia. Masyarakat menjadikan tradisi lisan sebagai wadah untuk menyampaikan pesan-pesan dan nilai-nilai yang dapat dijadikan sebagai "hukum" tidak tertulis dan sumber pengetahuan manusia.

Kehidupan sastra lisan bagi masyarakat Dayak Paser merupakan satu bagian yang penting karena berkaitan dengan tradisi adat di masyarakat. Dalam perkembangan kehidupan sastra secara keseluruhan tidak dapat dilepaskan dari sastra tradisional setiap daerah. Sastra daerah merupakan peninggalan budaya masyarakat bangsa kita yang tidak ternilai harganya (Effendi, 2011:87). Fungsi sastra daerah adalah sebagai penunjang perkembangan bahasa daerah dan sebagai pengungkap alam pikiran, sikap, dan nilai-nilai kebidayaan masyarakat pendukungnya. Dari sekian hal mengenai sastra lisan Dayak Paser, yang menjadi objek penelitian ini adalah mantra.

Tipong Tawar merupakan sebuah mantra yang digunakan dalam ritual-ritual adat suku Dayak Paser. Salah satu ritual tersebut adalah ritual pertanian yang dilakukan oleh masyarakat Dayak Paser sejak dulu yang masih dilestarikan hingga sekarang. Mantra Tipong Tawar bagi keyakinan masyarakat Desa Baras Jiring sebagai media perantara antara keinginan dari masyarakat kepada Tuhan yang Maha Kuasa.

Tipong Tawar adalah sebuah media berupa beras yang disebut tepung yang diletakkan di dalam mangkok kecil putih. Tepung tersebut diberi nama Tipong Tawar. Tipong artinya adalah tepung (dalam bahasa Indonesia) mempunyai definisi yang berdasarkan pada KBBI (online/daring) yaitu sebuah barang yang dilumat-lumat (karena ditumbuk, digiling, dan sebagainya), tepung yang berbahan 
dasar beras atau serbuk yang lumat. Sedangkan Tawar dalam KBBI (online/daring) mempunyai definisi yaitu tidak ada rasanya, kurang asin, kurang sedap (tentang makanan), hambar. Namun dalam hal kegunaan sebagai media dalam ritual adat dipakai istilah tawar yang artinya sebagai obat atau penawar. Oleh karena itu, Tipong Tawar adalah media obat atau penawar yang telah diberi mantra atau jampi-jampi oleh Balian (dukun/pawang) dalam setiap ritual adat.

Kehadiran suatu mantra berkaitan erat dengan kepercayaan manusia dengan dunia gaib dan dunia supranatural. Menurut Djamaris (1990:20), mantra itu tidak lain adalah suatu gubahan bahasa yang diresapi oleh kepercayaan kepada dunia yang ghaib dan sakti. Gubahan bahasa dalam mantra itu mempunyai seni kata yang khas pula. Kata-katanya dipilih secermat-cermatnya, kalimatnya tersusun dengan rapi, begitu pula dengan iramanya. Ketelitian dan kecermatan memilih kata-kata, menyusun larik, dan menetapkan iramanya itu sangat diperlukan terutama untuk menimbulkan tenaga gaib. Tujuan utama dari suatu mantra adalah untuk menimbulkan tenaga gaib. Dengan kata lain bahasa dalam mantralah yang diyakini mendatangkan kekuatan supranatural untuk berkomunikasi dengan dewa-dewa atau roh halus. Mantra biasanya berhubungan dengan kepercayaan masyarakat yang animisme.

Mantra dikenal sebagai sebuah kumpulan kata yang mengundang efek kekuatan gaib. Mantra diucapkan oleh seorang Balian (dukun/pawang). Pengucapan sebuah mantra harus didukung pula oleh konteks penuturannya artinya mantra tidak boleh diucapkan di sembarang tempat, misalnya dalam setiap upacara-upacara ritual. Dalam upacara ritual, mantra digunakan sebagai sarana untuk berkomunikasi dengan Tuhan, Dewa, leluhur, atau makhluk gaib lainnya.

Membaca mantra merupakan salah satu upaya untuk memohon perlindangan kepada Tuhan yang Maha Kuasa, baik secara langsung maupun melalui perantara makhluk gaib. Pembacaan mantra biasanya dipimpin oleh seorang pawang atau dukun atau belian yang dianggap pintar atau sakti yang dapat menghubungkan dunia alam gaib dengan manusia. Pembacaan mantra bisanya diiringi dengan nyanyian atau alat musik khas Dayak.

Mantra Tipong Tawar adalah salah satu mantra yang berkembang di Suku Dayak Paser. Mantra ini digunakan pada upacara pertanian Dayak Paser. Meskipun sudah tidak berkembang di masyarakat Paser modern, namun ada beberapa daerah di Paser masih mengembangkan tradisi upacara tersebut. Daerah yang mengembangkan tradisi upacara pertanian adalah Desa Baras Jiring, Kecamatan Muara Komam, Kabupaten Paser, Kalimantan Timur.

Desa Baras Jiring terletak di Kecamatan Muara Komam, Kabupaten Paser, Kalimantan Timur. Desa Baras Jiring merupakan daerah yang cukup luas sekitar $9 \mathrm{~km}$ persegi di bagian timur berbatasan dengan wilayah Desa Uko daerah gunung Sodan dan 
berbatasan dengan sungai Komam (Bety, 2012:10). Meskipun wilayah Desa Baras Jiring yang cukup luas namun masih sepi untuk dikatakan sebagai tempat tinggal penduduk. Karena wilayah tersebut masih banyak ditanami kebun, sawah serta hasil ladang lainnya. Masyarakat Baras Jiring masih melestarikan adat tradisi pertaniannya dengan menggelar sebuah upacara atau ritual. Setiap tahunnya masyarakat Dayak Paser Desa Baras Jiring masih melakukan tradisi pertanian untuk menghormati para leluhur dan Tuhannya karena di dalam masyarakat Baras Jiring masih mempercayai adanya makhkuk gaib yang mendiami alam semesta. Oleh karena itu, dalam setiap ritual atau upacara selalu menggunakan mantra sebagai medianya.

Mantra Tipong Tawar merupakan bentuk sastra lisan yang disampaikan pada saat melakukan ritual pertanian ketika menanam padi hingga memanen padi (pesta panen). Ritual pertanian ini merupakan sebuah upacara ritual. Bahkan masyarakat Desa Baras Jiring menganggap bahwa sebelum dibacakan mantra Tipong Tawar maka ritual pertanian tersebut belum dapat dikatakan sah.

Upacara ritual lebih tepat untuk menunjuk ke teori adalah kegiatan yang dilakukan sehubungan dengan peristiwa penting yang pernah terjadi yang erat kaitannya dengan mitologi atau legenda. Upacara ritual merupakan salah satu bentuk dari sebuah pertunjukan (pentas). Istilah pertunjukan (pentas) adalah beberapa perkumpulan yang disampaikan dalam bentuk artistic-action (karya seni peran) yang dilakukan dalam folklor dan artistic event (peristiwa dalam karya seni) situasi pertunjukan, keterlibatan pemain, bentuk seni (art form), penonton (audience), dan setting sebagai pusat pengembangan pendekatan pertunjukan (performance) dalam folklor (Hymes, 1974:34).

Penampilan untuk pembacaan mantra biasanya dilakukan oleh seorang Balian (dukun/pawang) yang tentu saja sarat dengan ilmu kemistikan. Penampilan pembacaan mantra biasanya dilakukan ketika tiba masa Nasok Nias (menanam padi) dan Nyambat Taon (panen) di area menanam padi serta di rumah yang mempunyai hajat ketika masa panen (Rusbiyantoro, 2014:180\&281) . Ketika menanam padi atau masa panen padi, pemangku hajat biasanya mengundang tetangga sekitarnya untuk ikut melaksanakan acara tradisi pertanian tersebut. Para tetangga atau sanak keluarga yang datang dan diundang memberikan partisipasinya yaitu membantu menanam padi ketika masa tanam padi, juga membantu menyediakan bahan-bahan sajian ketika masa panen tiba.

Sebagai bagian dari folklor, sastra lisan yang berupa mantra Tipong Tawar yang dituturkan oleh Balian (dukun/pawang) merupakan salah satu sastra lisan yang mirip syair berbahasa Paser. Balian (dukun/pawang) memilih diksi yang unik dan khas agar menarik saat ditampilkan. Hal inilah yang memunculkan keingintahuan untuk mendeskripsikan bentuk dan struktur teks mantra Tipong Tawar pada ritual pertanian Dayak Paser.

Teks mantra Tipong Tawar mempunyai bentuk dan struktur yang berbeda jika dibandingkan dengan bentuk dan struktur puisi 
pada umumnya. Teks mantra Tipong Tawar menggunakan bahasa daerah Paser yang tentu saja membuat struktur teksnya berbeda dengan struktur teks bahasa Indonesia.

Munculnya pendekatan bentuk teks tidaklah dapat dilepaskan dari peran kaum formatif Rusia, karena itu kaum formatif dipandang sebagai peletak dasar telaah sastra dengan pendekatan ilmu modern. Ciri khas penelitian sastra kaum formatif adalah perhatiannya terhadap apa yang merupakan suatu yang khas dalam karya sastra yang terdapat dalam karya sastra dalam teks bersangkutan. Dalam hal ini nilai estetika suatu karya sastra seperti yang dikemukakan oleh tokoh utamanya Jakobson adalah didasarkan pada Poetic Function yang diolah berdasarkan kode metrum, rima, macam-macam bentuk paraletisme, pertentangan, kiasan dan sebagainya. Karya sastra dipandang sebagai suatu yang otonom. Secara umum struktur puisi (mantra) dibagi ke dalam: unsur yang membangun dalam puisi ada dua yakni unsur intrinsik dan ekstrinsik, kedua unsur tersebut tidak dapat dipisahkan. Berkaitan dengan unsur batin, puisi memiliki unsur intrinsic.

Bentuk fisik puisi adalah medium untuk mengungkapkan makna yang hendak disampaikan penyair. Bangun suatu bentuk puisi (mantra) adalah unsur pembentuk puisi yang dapat diamati secara visual. Unsur tersebut meliputi: (1) bunyi, (2) kata, (3) lirik atau baris, (4) bait, dan (5) tipografi yang dikemukakan (Aminuddin, 2011:136).

Bentuk bangun tersebut sebagai salah satu unsur yang dapat dinikmati secara visual karena dalam puisi juga terdapat unsurunsur yang hanya dapat ditangkap lewat kepekaan batin dan daya kritis pikiran pembaca. Unsur tersebut pada dasarnya dapat merupakan unsur tersembunyi dibalik apa yang dapat dinikmati secara visual yang dapat disebut sebagai lapis makna puisi. Selanjutnya dari segi bentuk fisik puisi yang telah dikemukakan di atas, Tjahjono mengatakan bahwa unsur fisik puisi meliputi: (1) bunyi dan irama, (2) diksi atau pilihan kata, (3) baris dalam puisi, (4) enjabemen, (5) bait dan (6) tipografi (Tjahjono, 1988:44). Adapun bentuk dalam mantra terdiri dari: tema, bunyi, baris, bait dan diksi.

Hoed (2011:29) menyatakan bahwa struktur merupakan bangun abstrak yang terdiri atas sejumlah komponen yang berkaitan satu sama lain di dalam susunan tertentu. Kaitan tersebut disebut relasi, setiap komponen salin g mendukung antara satu dan lainnya.

Mantra Tipong Tawar merupakan salah satu sastra lisan Dayak Paser penting dikaji karena beberapa alasan. Pertama, mantra Tipong Tawar terdapat di tengah-tengah kehidupan masyarakat Paser. Kedua, mantra Tipong Tawar tersebut mampu menciptakan kekeluargaan serta kegotongroyongan antar saudara dan tetangga. Hal ini dapat dibuktikan bahwa ketika melaksanakan ritual pertanian terjadi saling bahu membahu untuk menyelesaikan pekerjaan menanm padi atau memanen padi. Ketiga, mantra Tipong Tawar mempunyai bentuk dan struktur yang berbeda dari bentuk dan struktur puisi pada umumnya. Keempat, mantra Tipong Tawar 
menyampaikan keinginan-keinginan, aturan-aturan sosial, menasihati serta kebenaran-kebenaran yang diyakini oleh masyarakat Dayak Paser sebagai produk budaya lisan.

Amir (2013:19) menjelaskan bahwa alasan pertama sastra lisan ada dan terus hidup di tengah masyarakat sebagai produk budaya lisan. Kedua, dari sudut pandang folklor, sastra lisan dapat dilihat dari dua fungsi, (1) sastra lisan berfungsi untuk membangun dan mengikat rasa persatuan kelompok; (2) sastra lisan menyimpan kearifan lokal. Ketiga, memperlihatkan hubungan antara kebudayaan dengan kebudayaan lain. Keempat, sastra lisan dapat mewakili bangnsa untuk bersanding dengan sastra lisan dari negara lain.

Berdasarkan fenomena tersebut, mantra Tipong Tawar yang merupakan sastra lisan Dayak Paser, sangat menarik apabila dikaji dari aspek bentuk dan struktur sastra lisan. Oleh karena itu, permasalahan dalam penelitian ini adalah bagaimana bentuk dan struktur teks mantra Tipong Tawar dalam ritual pertanian Dayak Paser. Sedangkan tujuan dari penelitian ini adalah mendeskripsikan bentuk dan struktur teks mantra Tipong Tawar dalam ritual pertanian Dayak Paser.

METODE

Penelitian ini adalah penelitian lapangan. Jenis penelitian ini menggunakan penelitian kualitatif. Metode yang digunakan adalah metode deskriptif dengan pendekatan etnografi. Teknik pengumpulan data dalam penelitian ini menggunakan teknik pengamatan, wawancara, perekaman, dan pencatatan. Teknik analisis data dalam penelitian ini dengan menggunakan teknik analisis deskriptif yang mengacu pada teknik analisis data menurut Endraswara (2009:108) menjelaskan bahwa dalam teknik analisis data folklor meliputi teknik mandiri dan teknik interdisipliner yang artinya adalah mendeskripsikan data folklor dengan mengaitkannya dengan bentuk serta unsur-unsur kebudayaan bangsa.

Dalam upaya transkripsi, untuk mendapatkan mantra Tipong Tawar dalam ritual pertanian Dayak Paser yang utuh sebagai sebuah mantra yang memiliki bentuk dan struktur teks, maka peneliti menyunting mantra berdasarkan ucapan dari Balian (dukun) dalam ritual pertanian Dayak Paser yaitu sebagai informan. Prosedur analisis data dalam penelitian ini yakni, 1) Hasil rekaman ditranskripsikan yakni diubah dari lisan kedalam bentuk tulisan. Teknik transkripsi adalah teknik menyalin atau turunan tanpa menggantikan jenis (huruf tetap sama). 2) Data yang telah ditranskripsi kemudian diterjemahkan. Terjemahan yakni mengubah hasil transkripsi tulis yang berbahasa asli Paser ke dalam Bahasa Indonesia.

Pada penelitian ini, teks mantra yang telah ditranskripsikan akan diterjemahkan peneliti secara literal agar teks dapat dibaca dan dipahami tanpa mengubah konteks aslinya. Penyajian terjemahan mengikuti model yang disarankan Hutomo (1991:90), yaitu (1) teks asli ditampilkan disebelah kiri kemudian teks terjemahan ditampilkan disebelah kanan, dan (2) teks asli ditampilkan di atas, 
kemudian teks terjemahan di bawahnya. Dalam penelitian ini akan mengikuti model yang pertama yaitu teks asli ditampilkan di sebelah kiri, kemudian teks terjemahan ditampilkan di sebelah kanan.

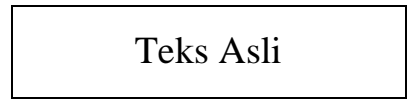

(3) Setelah diterjemahkan, data diidentifikasi dan diklasifikasikan sesuai dengan fokus penelitian yaitu mendeskripsikan struktur dan bentuk teks mantra Tipong Tawar dalam ritual pertanian Dayak Paser.

\section{PEMBAHASAN Proses Pelaksanaan Pertanian Dayak Paser}

Proses pelaksanaan pertanian pada masyarakat Paser Desa Baras Jiring atau istilah lainnya adalah cara bercocok tanam. Cara bercocok tanam masyarakat Baras Jiring masih banyak dipengaruhi oleh ilmu dukun (Belian), Proses pelaksanaan upacara pertanian Paser dilakukan dengan cara penebasan, penebangan, pembakaran, penyiangan, serta ditugal dengan kayu yang diruncingkan kemudian butir padi dimasukkan ke dalam lubang tugalan (lubang untuk siap diberi benih tanaman). Proses pelaksanaan upacara pertanian tersebut terdiri dari beberapa tahapan yaitu:

a) Meresa Tana (memeriksa tanah)

Meresa Tana merupakan proses dalam meninjau lokasi untuk melihat dari dekat bagaimana keadaan lokasi dan kesuburan tanah yang akan dijadikan tempat ngumo (berladang). Cara memeriksa kesuburan tanah yaitu mencabut kayu sebesar telunjuk di beberapa tempat. Apabila kayu tersebut mudah ditarik berari daerah itu subur. Kemudian tanah dilihat apakah merah atau hitam, jika hitam berarti subur, jika merah atau kuning berarti tanah tersebut kurang subur.

b) Nuntun Tana (bermusyawarah)

Nuntun Tana berarti adalah musyawarah. Sebelum dilakukan penanaman padi atau bercocok tanam, para masyarakat atau kepala keluarga yang akan berladang dengan kepala adat setempat melakukan musyawarah untuk penentuan hari baik atau buruk dalam kegiatan bercocok tanam.

Mereka bepekat (bermusyawarah/bersepakat) untuk menentukan tana (menjenguk tanah lokasi) untuk mengetahui apakah ada tanda-tanda atau isyarat yang tidak baik dari lam atau makhluk lainnya. Apabila tidak ada tanda atau isyarat yang tidak baik, maka segera nyetaris (memberi batas) pada satu sama lain, yang artinya lokasi siap untuk digarap (dikerjakan). Setelah aara peninjauan tersebut selesai, kemudian mereka pulang ke rumah masing-masing.

Dengan menghitung tanggalan (kalender) dan hari dalam melaksanakan pekerjaan bercocok tanam seperti itu perlu diperhatikan awal dari setiap perhitungan hari baik dan buruknya untuk melakukan sesuatu dengan menggunakan alat- 
alat yang terlebih dahulu dibacakan sebuah mantra. Mantra untuk upacara pertanian pada masyarakat Paser disebut Tipong Tawar.

Seperti yang telah dijelaskan bahwa dalam melaksanakan cocok tanam terlebih dahulu ditentukan perhitungan hari yang baik dan buruknya. Beberapa kepala keluarga atau serikat mengadakan bepekat (bermusyawarah/bersepakat) untuk menentukan tempat berladang; apakah di alas tuwo (hutan besar) ataukah di lati (hutan kecil atau ladang atau hutan bekas berladang yang ditinggalkan selama beberapa tahun saja), maksudnya untuk membuat subur kembali tanah dan untuk mengurangi tumbuhnya rumput/gulma yang akan mengalahkan padi.

Apabila disepakati menggarap alas tuwo (hutan besar), maka perlu mengadakan sabi-seba (ungkapan permisi) kepada penghuni atau penguasa hutan, yakni makhluk halus, binatang, tanah, air, rumput, batu, kayu hidup serta kayu mati. Adapun dalam pelaksanaan sabi-seba tersebut diperlukan beberapa alat untuk upacara tersebut. di antaranya adalah minyak kelapa secukupnya di dalam mangkok putih, sebutir telur ayam kampung, kayu merah (karumbulu), beras kuning, perapen yang berisi api. Alat-alat inilah yang disebut Jombu (sesaji) yang berfungsi sebagai tanda penghormatan, dan dapat menembus dinding ke-ghaib-an.

c) Nguarong (membuat arang dari kayu ulin)

Nguarong adalah membuat arang dari kayu ulin yang telah mati yang berada di dalam hutan. Untuk mencari kayu ulin tersebut, mereka bersama-sama pergi ke dalam hutan lalu membuat arang. Dalam membuat arang, mereka biasanya bermalam antara dua sampai tiga malam. Karena peralatan untuk membelah dan memeotong batang kayu ulin tersebut sangat sederhana yaitu dengan wase/belayung (pahatan), paji (pasak), otak (parang), dan gergaji tangan.

Parang yang akan digunakan untuk menebas kayu ulin terlebih dulu disepuh supaya tajam, tidak tertinggal juga sebuah wase/belayung (pahatan). Mata belayung terbuat dari besi baja atau yang dianggap cukup kuat dan tajam, tangkai wase/belayung terbuat dari akar ganggang, ponjot (anyaman) tangkai belaying dari rotan berlapis dua, dibagian ujungnya dibuat dada upan (dada belalang), wase siap untuk digunakan.

Kayu ulin (telion) ditumpuk berselang satu berbentuk persegi empat dan ditancapkan kayu berdaun lebar ditengahtengahnya. Hal ini dapat membrikan isarat banyak atau tidaknya pada tahun depan mendapat padi.

Dalam melaksanakan nguarong, terdapat beberapa larangan terutama berkaitan dengan waktu. Larangan tersebut di antaranya adalah berbaring, menangis, berkata ceroboh, menakut-nakuti teman, membunuh binatang apapun, marah pada api, marah karena hujan dan angin yang deras. 
Setelah arang dingin, maka arang dikumpulkan ke dalam suatu tempat yang disebut bangkat yang terbuat dari kayu sebesar telunjuk dijalin dengan rotan kemuadian arang dibawa pulang ke rumah.

d) Tukung Mombas (menebas/memetong)

Sebelum memulai menebas, terlebih dahulu menghitung bulan berapa malam timbul disesuiakan dengan hari, waktu tersebut biasanya disebut dengan ngembilang, yaitu sambil menghitung pada lambing-lambang tulisan Paser Kuno yang disebut Raja Segendar. Tulisan tersebut meruoakan warisan turun-temurun dari jaman Paser Kuno sampai sekarang. Bahkan terpendam di dalam gunung karena rumah orang Dayak Paser yang pada zaman itu adalah Goa (liang) yang terdapat di gunung Batu.

Setelah mengetahui waktu yang baik, maka segera memulai menebas. Dalam proses menebas, dipilihlah satu pohon yang dianggap baik. Disitulah mulai naris kayu notok doroi (berdoa kepada sang pencipta), doa tersebut diucapkan seraya memohon kepada Tuhan agar diberikan keberkahan, keselamatan seluruh anggota keluarganya dalam menjalani kehidupan ini.

Menebas biasanya dilakukan dengan cara bergotong royong (empolo) secara bergiliran. Tidak tertinggal pula para ibu dan remaja putri untuk membantu dalam hal memasak, memberi makanan dengan senang hati seiring dengan itu terbesit juga dihati mereka kata-kata "tengkuwen panyumbolum taka” (perbaiki kehidupan kita).

e) Notou (menebang)

Notou adalah menebang pohon yang ada di lokasi lading tersebut. Proses notou dibagi menjadi dua:

1) Ngndoroi yaitu menebang kayu yang agak kecil yang sekiranya dapat dipotong/ditebang dengan parang.

2) Notou yaitu menebang kayu yang berukuran besar menggunakan wase/belayung (pahatan) yang bertangkai akar (bako ganging), pasulumu lutung, ponjot uwe.

Menebang biasa dilakukan dengan empolo (gotong royong) secara bergiliran hingga pekerjaan selesai. Kayu yang ditebang dahan-dahannya jentok (dicecang) agar dahan kayu bisa terbakar waktu membakar.

f) Ngeke Jowa (pohon yang ditebang)

Ngeke Jowa berarti pohon yang ada dilokasi lading telah habis ditebang, maka tibalah masa penjemuran pohon diladang untuk menunggu waktu pembakaran. Sambil menunggu keringnya kayu di ladang, anggota bepekat (musyawarah) untuk membuat batasan api yang disebut Ngoak/Nelatas untuk mencegah terjadinya keakaran ke luar lokasi ladang. Hal ini dilakukan dengan bergotong royong. Ngeke Jowa bisa dilakukan sampai dua bulan, biasanya bulan ke 8 dan 9 . 
g) Neket (membakar)

Neket (membakar) adalah sebuah kegiatan yang dilakukan apabila telah tiba waktu untuk membakar berdasarkan hasil musyawarah maka semua anggota turur serta turun di sekitar lokasi lading sambil membawa tembuluk bambu (tempat seperti bambu) berisi air gunanya untuk menyiram apabila ada api yang ke luar lokasi atau ada api yang memakan batang jabuk maka disiram dengan air dalam bambu tersebut.

h) Monduk (penyiangan)

Monduk atau manduk merupakan penyiangan sisa-sisa kayu yang terbakar waktu membakar. Kayu sisa kebakaran itu ditumpuk dan dibakar hingga selesai secara keseluruhan satu ladang. Monduk ini bisa dilakukan dengan bergotong royong. Para ibu biasanya memasak sayur dan lain sebagainya.

i) Nasok Nias (menanam)

Nasok Nias artinya menugal (membuat lubang). Sebelum pelaksanaannya, pertama, ngadek tukang pengulo (mengambil orang yang dianggap bisa untuk memberangkatkan padi/menanam dan mempunyai mantra menanam padi serta mempunyai lenga (minyak) sengkui yaitu minyak anti kejahatan, anti penyakit padi, anti guna-guna yang ditujukan pada tanaman padi tersebut.

Membuat teniam (pondok padi) sebagai tempat meletakkan padi di ladang, dihiasi dengan daun sebagai anti penyakit padi yang disebut tapis teniam. Adakalanya di depan teniam dipasang bendera dari sarung yang disebut lelayur untuk diturunkan oleh orang yang menginginkannya, maksudnya adalah untuk memeriahkan secara nasok-nias, pakaian bebas pantas yang laki-laki memakai Mandau dan yang perempuan membawa peruan penias (tempat benih padi).

Kegiatan Nasok adalah salah satu kegiatan yang menggunakan kayu yang diruncingkan sebagai alat tugalan untuk membuat lubang yang akan didisi benih padi. Kegiatan ini dilakukan oleh para bapak, para remaja putra, para anak lelaki dengan berdiri dan berderet ke arah samping kiri dari seseorang yang bertugas Moit Wae, ia berhak untuk mengatur luas yang ditugal (dibuat lubang) dalam satu kali gerak naikturun juga disesuaikan dengan jumlah peserta penugal, bergerak ke arah depan, samping kiri dan kanan untuk membantu teman yang ada di kiri dan kanan.

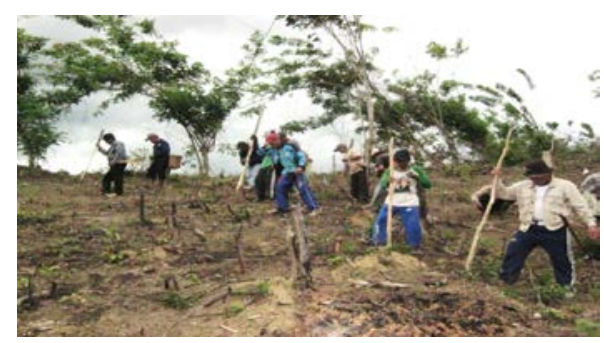

Gambar 1. Kegiatan Nasok 
Kegiatan nias adalah suatu kegiatan mengisi benih padi ke dalam lubang tugalan yang dilakukan oleh para ibu, para remaja putri, dan anak-anak dengan membawa peruan penias sebagai tempat padi yang diambil dari seseorang yang disebut ine pare (ibu padi), dia bertugas untuk mengambil dan membawa padi dari tenian yang akan diberikan atau dibagikan kepada anggota penias.

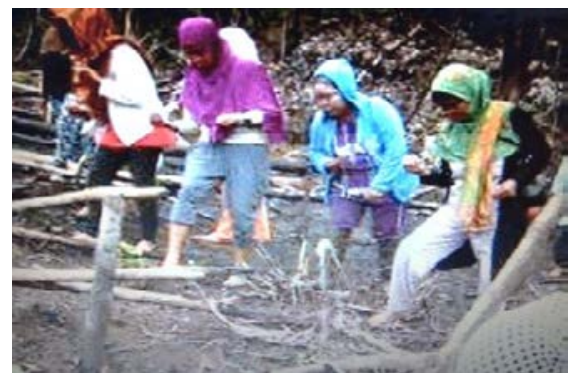

Gambar 2. Kegiatan Nias

Ciri-ciri tempat yang dibawa oleh ine pare (ibu padi) adalah pada lanjung kecilnya terselip daun sarumbolum dan kombat (daun cocor bebek dan daun kambat).

Setelah wae (padi) habis maka dilanjutkan dengan yang disebut nyorong galang, artinya adalah memasuki tahapan berikutnya. Setelah selesai nyorong galang kemudian memasuki kegiatan memasuki pondok padi (tenian). Padi ditutup dengan torung (kain merah dan kain hitam) dan tidak tertinggal di sampingnya tepung tawar (Tipong Tawar).

Kemudian, pawang mendendangkan atau membacakan mantra dengan maksud agar segala sesuatu yang telah dikerjakan tidak sia-sia. Dan sesuatu hal yang kurang bagus akan dibuang agar tidak menjadikan sebuah kesialan pada kehidupan para petani atau orang yang akan berladang. Berikut adalah mantranya.

\begin{tabular}{|c|c|}
\hline Teks Asli & Teks Terjemahan \\
\hline ede iko mana kamurio lonsa tom ban & ini kamu membuang naas \\
\hline jiang ontun puli sala dion & dengan beberapa obat (padi) \\
\hline ede iko mana bubuk bua bukon & $\begin{array}{l}\text { ini kamu membuang bubuk } \\
\text { (buah yang tidak jadi) }\end{array}$ \\
\hline mana jawas bua ore & $\begin{array}{l}\text { membuang kesialan buah yg } \\
\text { kecil yang tidak jadi }\end{array}$ \\
\hline selanu bung bua latu & seluruh buah-buahan yang jatuh \\
\hline jerupang-jeruping, jementa-jemento & $\begin{array}{l}\text { jerupang-jeruping, jementa- } \\
\text { jemento }\end{array}$ \\
\hline jementa tete iwa, jemento tete ombo & lewat bawah, lewat atas \\
\hline palai angin, ine Nyonsai, jiang riut & $\begin{array}{l}\text { lewat angin, ibu Nyonsai, } \\
\text { dengan angina }\end{array}$ \\
\hline utut jombu, ruko iko ajin bias & $\begin{array}{l}\text { asap perapian/prapen jombu, } \\
\text { bangun kamu beras kuning }\end{array}$ \\
\hline
\end{tabular}




\begin{tabular}{|c|c|}
\hline Teks Asli & Teks Terjemahan \\
\hline nyolis-nyolang dayang luing & $\begin{array}{l}\text { ingin bangun pengikut ratu } \\
\text { menyuruh }\end{array}$ \\
\hline $\begin{array}{l}\text { iko te wase sampe, iko te wase } \\
\text { nyampe }\end{array}$ & $\begin{array}{l}\text { kamu untuk menyampaikan } \\
\text { pesan }\end{array}$ \\
\hline apan lio kati olo & supaya bersih seperti siang hari \\
\hline melintai kati bulan & seperti terang bulan purnama \\
\hline solo belo taurtiok & tidak ada terttup oleh awan \\
\hline bulan belo kambuh jaon & bulan tidak terhalang awan \\
\hline lio lolo belo keo kamu & terang seperti hari benderang \\
\hline rio lonsa ontun puli & tidak ada masalah lagi \\
\hline belo keo kendulu utok & tidak ada sakit kepala \\
\hline belo keo beleleng wae & tidak ada pusing muka/wajah \\
\hline belo keo layong molo & tidak ada panas (matahari) siang \\
\hline belo keo mekom malom & $\begin{array}{l}\text { tidak ada demam pada malam } \\
\text { hari }\end{array}$ \\
\hline apan roni damurowe & supaya dingin perasaan \\
\hline apan rempai damuria & supaya enak perasaan \\
\hline apan rempai ngarumpayon & supaya sehat selalu \\
\hline apan tonga lio lonik & supaya badan bersih \\
\hline naket sen kuli sen & mencari uang dapat uang \\
\hline enjulang kuli buau & mendulang dapat emas \\
\hline ngumo kuli pare bias & berladang dapat padi dan beras \\
\hline roni danum lindok lumut & $\begin{array}{l}\text { dinginnya air kali Gunung } \\
\text { Lumut }\end{array}$ \\
\hline telaga lindok liang & dinginnya air telaga \\
\hline senang renda kelokor koyong & senang gembira riang \\
\hline batang ori tonga, derie melas lalung & badan tubuh ini (jasad dan roh) \\
\hline $\begin{array}{l}\text { tindu nang kendulu utok-beleleng } \\
\text { wae }\end{array}$ & meminta jangan sakit kepala \\
\hline nang keo roton-rodot & $\begin{array}{l}\text { jangan ada sakit lagi pusing } \\
\text { kepala }\end{array}$ \\
\hline julai-jemalai & terasa kaku, badan kaku \\
\hline jail-jungel & $\begin{array}{l}\text { baik yang keras maupun yang } \\
\text { tidak }\end{array}$ \\
\hline tutur-tumbak & luka tersandung kayu \\
\hline penempong kayu-penoyak putuk & $\begin{array}{l}\text { mudik sampai ke hulu, milir } \\
\text { sampai ke hilir }\end{array}$ \\
\hline $\begin{array}{l}\text { murek sampe dayo-mandor sampe } \\
\text { olong }\end{array}$ & $\begin{array}{l}\text { sampai ke muara, tdk ada } \\
\text { permasalahan }\end{array}$ \\
\hline erai batang taondo & satu tahun yang berjalan \\
\hline tindu nupi buen baya & minta mimpi bulan baru \\
\hline
\end{tabular}




\begin{tabular}{|l|l|}
\hline \multicolumn{1}{|c|}{ Teks Asli } & \multicolumn{1}{c|}{ Teks Terjemahan } \\
\hline tindu uyat lolang ukur & minta urat kuat kekuatan \\
\hline tindu rejeki mura & minta rejeki murah \\
\hline tindu pencarian juga & minta pencaharian yang mudah \\
\hline
\end{tabular}

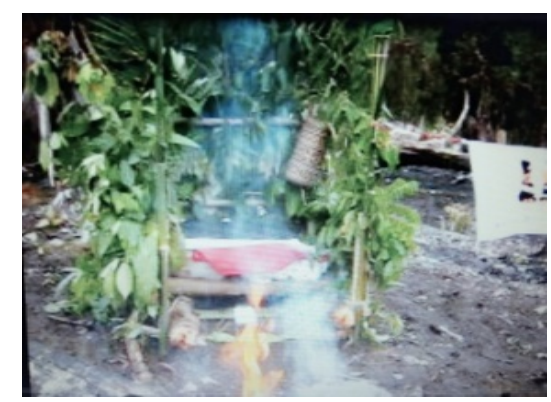

Gambar 3. Tenian (tempat padi)

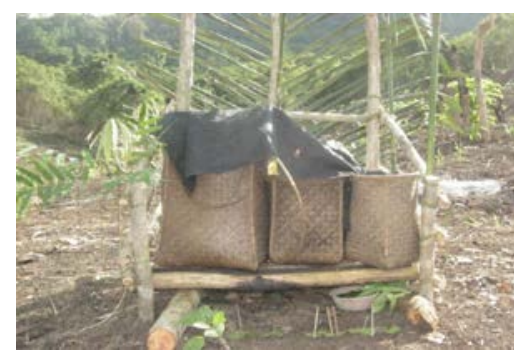

Gambar 4. Tenian (tempat padi)

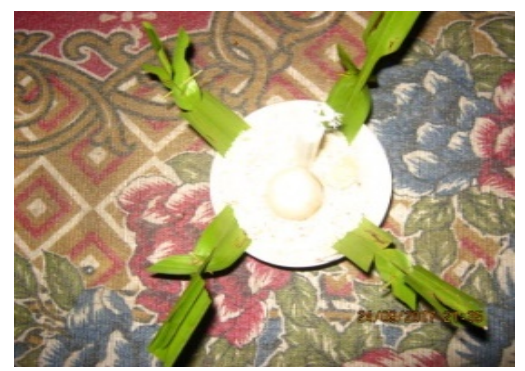

Gambar 5. Tepung Tawar

Tipong tawar berguna untuk menawarkan atau untuk membuang naas, kecerobohan yang tidak terasa terucap oleh peserta penugal dan penias dan kejadian lainnya.

j) Nyambat Taon (berhajat/panen)

Acara terakhir dalam upacara pertanian. Upacara tersebut wajib dibayar pada akhir atau selesai masa panen. Dalam melaksanakan upacara nyambat taon terdapat jajanan bermacam-macam dan berwarna (jajaj warna), makanan tersebut harus ada sembilan macam (jajaj walu warna sembilan peteri mendi).

Nama-nama jajan atau makanan tersebut di antaranya adalah: Wajik, dodol merah dan putih, pais merah dan putih, buah sepang merah dan putih, onde-onde, angka walu (angka 8) merah dan putih, kekicak merah dan putih, cucur, peteri mendi. Adapun iringan jajan (makanan) tersebuat adalah, deli piak (sayur ayam), peranggang piak (ayam panggang), tekulus (lemang), ketapak putih dan merah, sesagon, dadar toil (dadar 
telur), kelapa ulong, danum ulong langit (air kelapa), toil tutuk, ruang opat, ruang walu, daon dirung (daun biowo). Kemudian Balian (dukun/pawang) mengucapkan sebuah mantra atau soyong (doa) ketika panen tiba dengan berbagai macam jenis makanan tersebut. Bacaan mantra tersebut dilakukan ketika panen padi mantra Tipong Tawar dibaca dengan tujuan agar padi yang dipanen mempunyai berkah dan agar padinya tahan lama dan tidak cepat habis karena cara mendapatkannya sulit atau susah. Mereka yang dikerahkan untuk turut memotong padi biasanya memperoleh bagian dari padi yang berhasil mereka potong.

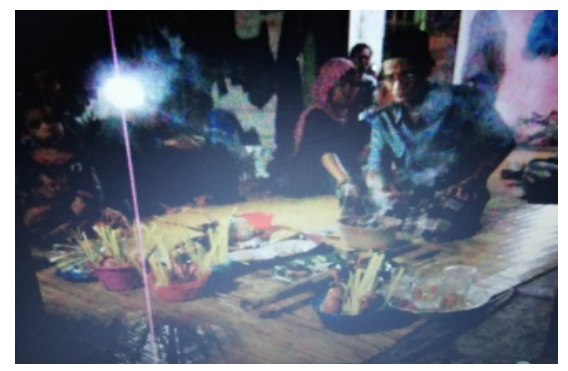

Gambar 5. Tepung Tawar

\section{Bentuk dan Struktur Teks Mantra Tipong Tawar}

Mantra Tipong Tawar dalam upacara pertanian suku Dayak Paser secara keseluruhan terbagi ke dalam 9 mantra dengan berbahasa Paser. Teks mantra yang dianalisis dibagi menjadi beberapa bagian berdasarkan tahap pengucapannya. Dalam struktur mantra Tipong Tawar ditemukan lima unsur pembangunnya. Unsur-unsur tersebut terdiri atas tema, formula bunyi (rima dan irama), bait, baris, dan diksi.

\begin{tabular}{|c|c|c|}
\hline No. & Teks Asli & Teks Terjemahan \\
\hline \multirow[t]{5}{*}{1.} & $\begin{array}{l}\text { ede iko mana kamurio lonsa } \\
\text { tom ban }\end{array}$ & ini aku membuang naas \\
\hline & jiang ontun puli sala dion & dengan beberapa obat (padi) \\
\hline & $\begin{array}{l}\text { ede iko mana bubuk bua } \\
\text { bukon }\end{array}$ & $\begin{array}{l}\text { ini aku membuang bubuk (buah yang } \\
\text { tidak jadi) }\end{array}$ \\
\hline & mana jawas bua ore & $\begin{array}{l}\text { membuang kesialan buah yg kecil yang } \\
\text { tidak jadi }\end{array}$ \\
\hline & selanu bung bua latu & seluruh buah-buahan yang jatuh \\
\hline \multirow[t]{5}{*}{2.} & $\begin{array}{l}\text { jerupang-jeruping, jementa- } \\
\text { jemento }\end{array}$ & jerupang-jeruping, jementa-jemento \\
\hline & $\begin{array}{l}\text { jementa tete iwa, jemento } \\
\text { tete ombo }\end{array}$ & lewat bawah, lewat atas \\
\hline & $\begin{array}{l}\text { palai angin, ine Nyonsai, } \\
\text { jiang riut }\end{array}$ & lewat angin, ibu Nyonsai, dengan angin \\
\hline & utut jombu, ruko iko ajin bias & $\begin{array}{l}\text { asap perapian/prapen jombu, bangun } \\
\text { kamu beras kuning }\end{array}$ \\
\hline & nyolis-nyolang dayang luing & ingin bangun pengikut ratu menyuruh \\
\hline
\end{tabular}


Tipong Tawar dalam Ritual Pertanian Dayak Paser: Sebuah Bentuk dan Struktur

\begin{tabular}{|c|c|c|}
\hline No. & Teks Asli & Teks Terjemahan \\
\hline & $\begin{array}{l}\text { iko te wase sampe, iko te } \\
\text { wase nyampe }\end{array}$ & kamu untuk mneyampaikan pesan \\
\hline \multirow[t]{6}{*}{3.} & apan lio kati olo & supaya bersih seperti siang hari \\
\hline & melintai kati bulan & Seperti terang bulan purnama \\
\hline & solo belo taurtiok & tidak ada terttup oleh awan \\
\hline & bulan belo kambuh jaon & bulan tidak terhalang awan \\
\hline & lio lolo belo keo kamu & terang seperti hari benderang \\
\hline & rio lonsa ontun puli & tidak ada masalah lagi \\
\hline \multirow[t]{4}{*}{4.} & belo keo kendulu utok & tidak ada sakit kepala \\
\hline & belo keo beleleng wae & tidak ada pusing muka/wajah \\
\hline & belo keo layong molo & tidak ada panas (matahari) siang \\
\hline & belo keo mekom malom & tidak ada demam pada malam hari \\
\hline \multirow[t]{4}{*}{5.} & apan roni damurowe & supaya dingin perasaan \\
\hline & apan rempai damuria & supaya enak perasaan \\
\hline & apan rempai ngarumpayon & supaya sehat selalu \\
\hline & apan tonga lio lonik & supaya badan bersih \\
\hline \multirow[t]{3}{*}{6.} & naket sen kuli sen & mencari uang dapat uang \\
\hline & enjulang kuli buau & mendulang dapat emas \\
\hline & ngumo kuli pare bias & berladang dapat padi dan beras \\
\hline \multirow[t]{4}{*}{7.} & roni danum lindok lumut & dinginnya air kali Gunung Lumut \\
\hline & telaga lindok liang & dinginnya air telaga \\
\hline & senang renda kelokor koyong & senang gembira riang \\
\hline & $\begin{array}{l}\text { batang ori tonga, derie } \\
\text { melas lalung }\end{array}$ & badan tubuh ini (jasad dan roh) \\
\hline \multirow[t]{8}{*}{8.} & $\begin{array}{l}\text { tindu nang kendulu utok- } \\
\text { beleleng wae }\end{array}$ & meminta jangan sakit kepala \\
\hline & nang keo roton-rodot & jangan ada sakit lagi pusing kepala \\
\hline & julai-jemalai & terasa kaku, badan kaku \\
\hline & jail-jungel & baik yang keras maupun yang tidak \\
\hline & tutur-tumbak & luka tersandung kayu \\
\hline & $\begin{array}{l}\text { penempong kayu-penoyak } \\
\text { putuk }\end{array}$ & $\begin{array}{l}\text { mudik sampai ke hulu, milir sampai ke } \\
\text { hilir }\end{array}$ \\
\hline & $\begin{array}{l}\text { murek sampe dayo-mandor } \\
\text { sampe olong }\end{array}$ & sampai ke muara, tdk ada permasalahan \\
\hline & erai batang taondo & satu tahun yang berjalan \\
\hline \multirow[t]{4}{*}{9.} & tindu nupi buen baya & minta mimpi bulan baru \\
\hline & tindu uyat lolang ukur & minta urat kuat kekuatan \\
\hline & tindu rejeki mura & minta rejeki murah \\
\hline & tindu pencarian juga & minta pencaharian yang mudah \\
\hline
\end{tabular}


Mantra mengikuti bentuk dan struktur puisi, maka mantra akan dikaji sebagaimana bentuk dan struktur yang membangun puisi yaitu: (1) tema, (2) bunyi, (3) baris , (4) bait, (5) diksi.

\section{Tema}

Tema adalah suatu yang diciptakan atau digambarkan oleh penyair atau dukun lewat mantra yang dihadirkannya. Pada dasarnya tema merupakan suatu yang harus dan pasti dalam mantra.

Pada dasarnya tema-tema yang terdapat dalam mantra tidak jauh dari tema kehidupan masyarakatnya, yakni tema agama, tema sosial, tema budaya, tema kemanusiaan. Demikian pula dengan mantra Tipong Tawar yang terdapat dalam upacara pertanian Paser. Mantra Tipong Tawar memiliki tema sentral yaitu tema kehidupan sosial masyarakat. Namun setiap larik mantra tentu saja mempunyai tema-tema yang berbeda didasarkan pada konteks penuturannya dan fungsinya. Seperti contoh pada kutipan mantra berikut ini:

\author{
ede iko mana kamurio lonsa tom ban \\ jiang ontun puli sala dion \\ ede iko mana bubuk bua bukon \\ mana jawas bua ore
}

selanu bung bua latu

\author{
ini aku membuang naas \\ dengan beberapa obat (padi) \\ ini aku membuang bubuk (buah yang tidak jadi) \\ membuang kesialan buah yg kecil yang tidak \\ jadi \\ seluruh buah-buahan yang jatuh
}

Tema mantra di atas adalah berkaitan dengan ajaran moral untuk melakukan sesuatu yang tidak berguna. Membuang atau melenyapkan sesuatu yang sudah tidak bermanfaat bagi kehidupan yang akan datang. Seperti yang tertulisa pada terjemahannya yaitu terdapat kata "ini aku" (ede iko) yang menjelaskan bahwasannya kita sebagai seorang manusia harus melakukan sesuatu hal yang sudah tidak berguna, yaitu dengan membuang sesuatu yang telah dianggap sial dalam kehidupan manusia. kesialan atau sial dapat diartikan sebuah buah yang jatuh.

\section{Bunyi}

Bunyi merupakan salah satu unsur yang membangun salah satu puisi akan memiliki keindahan dan maknanya serta kenikmatan akan didukung oleh unsur bunyi atau irama yang membentuk puisi tersebut. Berbicara tentang bunyi dalam puisi terlebih dahulu harus dipahami beberapa istilah yang berkaitan dengan bunyi, meliputi: rima adalah bunyi yang berselang atau berulang, baik dalam lirik maupun pada akhir lirik puisi. Rima mengandung beberapa aspek, yaitu:

a) asonansi (perulangan vokal)

Bunyi vokal adalah bunyi bahasa yang dihasilkan oleh arus udara dari paru-paru melalui pita suara dan penyempitan suara di atas glosit. Contoh asonansi perulangan vokal dalam mantra pertanian dapat kita lihat pada kutipan mantra seperti berikut:

jerupang-jeruping, jementa-jemento jerupang-jeruping, jementa-jemento jementa tete iwa, jemento tete ombo lewat bawah, lewat atas 
Dari mantra di atas dapat kita lihat perulangan vokal yang terjadi yaitu vocal (a) pada kata "jementa", huruf (o) pada kata "jemento" dan "ombo", huruf (e) pada kata "tete". Kata-kata pada mantra tersebut mempunyai arti yaitu sesuatu hal yang bisa datang dari arah bawah, arah atas pada suatu kehidupan. Bunyi pada mantra tersebut dibaca dengan sahdu seperti ketika kita membaca mantra pada jaman dahulu. Seperti juga ditemukan pada kutipan di bawah ini.

apan roni damurowe

apan rempai damuria

apan rempai ngarumpayon

apan tonga lio lonik supaya dingin perasaan

supaya enak perasaan

supaya sehat selalu

supaya badan bersih

Dalam kutipan mantra di atas terjadi perulangan huruf (a) pada kata "apan” yang mempunyai arti kata "supaya”. Makna dari kata tersebut adalah penegasan sebuah syarat untuk mendapakan harapan dari sesuatu yang diinginkan. Syarat tersebut harus dilakukan dengan penuh keyakinan seperti apa yang dimaksud atau sebagai tujuan.

b) aliterasi (perulangan bunyi konsonan)

Bunyi konsonan adalah bunyi bahasa yang dihasilkan dengan menghambat aliran udara pada salah satu tempat disalurkan suara di atas glottis. Perulangan bunyi konsonan dalam mantra dapat kita lihat dalam kutipan berikut:

belo keo kendulu utok tidak ada sakit kepala

belo keo beleleng wae tidak ada pusing muka/wajah

belo keo layong molo tidak ada panas (matahari) siang

belo keo mekom malom tidak ada demam pada malam hari

Pada kutipan mantra di atas terdapat perulangan bunyi konsonan pada huruf (b) dan huruf (k) kata "belo keo", yang mempunyai arti "tidak ada". Makna dari kutipan mantra tersebut adalah perulangan pada kata tidak ada. Perulangan kata tersebut dapat diartikan pula sebagai penegasan untuk sesuatu yang tidak akan terjadi serta tidak yang diharapkan oleh pembaca mantra dalam kehidupan yang akan datang.

c) rima akhir (paduan bunyi pada setiap akhir)

Paduan bunyi rima akhir dapat dilihat pada kutipan mantra berikut:

jerupang-jeruping, jementa-jemento jementa tete iwa, jemento tete ombo

jerupang-jeruping, jementa-jemento lewat bawah, lewat atas

Perulangan bunyi pada setiap akhir kata terdapat pada kutipan di atas yaitu kata "jementa tete iwa" dan "jemento tete ombo" lebih tepatnya pada huruf (a) pada kata "jementa” dan 
"iwa" dan huruf (o) pada kata "jemento" dan "ombo", serta huruf (e) pada kata "tete”. Bunyi tersebut menurut narasumber (Bapak Harpansyah) hanya sebagai pelengkap larik mantra. Namun tetap mempunyai arti yaitu segala sesuatu bisa datang melalui atas atau bawah.

\section{Baris dalam Mantra}

Baris atau larik dalam mantra adalah satuan yang pada umumnya lebih besar dari kata dan telah mendukung suatu makna tertentu. Baris dalam mantra pada dasarnya adalah merupakan pemadu, penyatu dan pengembang ide penyair yang diawali lewat kata. Akan tetapi sesuai dengan keberadaan baris dalam puisi makna penataan baris mantra harus memperhitungkan masalah rima serta penataan pola persajakan, seperti kutipan berikut:

naket sen kuli sen

enjulang kuli buau ngumo kuli pare bias mencari uang dapat uang

mendulang dapat emas

berladang dapat padi dan beras

Berkaitan dengan kata-kata yang dipilih dalam menciptakan mantra pertanian tersebut oleh oarang-orang pada saat itu lebih condong pada istilah sesuatu, seperti nama asal benda, musim, nama orang yang dianggap keramat, penyebutan angka, sejarah kejadian dan penyebab nama asal.

Dalam mantra pertanian ini mengandung sesuatu yang bersifat duniawi, yaitu harta benda dan mencari pekerjaan. Mantra tersebut di atas mengandung beberapa unsur, yaitu di antaranya ketika kita mencari uang hasilnya adalah uang, mencari emas dapatnya juga emas, berladang mendapatkan padi atau beras atau hasil ladanglainnya. Doa tersebut harus dibaca sewaktu memulai melakukan sesuatu yang baik, terlebih ketika melakukan sebuah nasihat pada catatan tersebut, karena doa tersebut adalah penghulu segala doa.

\section{Bait dalam Mantra}

Bait adalah kesatuan larik yang berada dalam suatu kelompok dalam rangka mendukung satu kesatuan pokok pikiran, terpisah dari kelompok larik (bait) lainnya (Aminuddin, 2011:145). Sebagaimana telah dijelaskan sebelumnya jumlah baris tiap-tiap mantra beragam, demikian juga dengan jumlah bait-baitnya. Dalam mantra dunia pertanian pada masyarakat Paser di desa Baras Jiring, khususnya mantra untuk Meresa Tana (memeriksa tanah yang dipakai untuk berladang), mantra Nuntun Tana (bermusyawarah untuk menentukan hari proses pelaksanaan ketika mulai berladang), mantra Tukung Mombas (menebas hutan yang akan dijadikan areal ladang bertani), Mantra untuk Naket (membakar kayu-kayu hutan), Mantra untuk Nyambat Taon (panen) tidak terlepas dari bait. Walaupun dalam satu dalam satu bait tidak tentu barisnya, ada yang, tiga baris, empat baris, lima baris, enam baris atau lebih. Kebanyakan dari mantra pertanian desa Baras 
Jiring terdiri dari beberapa bait saja, walau ada yang panjang melebihi dua, tiga, empat dan lima baris seperti contoh pada kutipan mantra berikut:

jerupang-jeruping, jementa-jemento jementa tete iwa, jemento tete ombo palai angin, ine Nyonsai, jiang riut utut jombu, ruko iko ajin bias

nyolis-nyolang dayang luing iko te wase sampe, iko te wase nyampe

\author{
jerupang-jeruping, jementa-jemento \\ lewat bawah, lewat atas \\ lewat angin, ibu Nyonsai, dengan angin \\ asap perapian/prapen jombu, bangun \\ kamu beras kuning \\ ingin bangun pengikut ratu menyuruh \\ kamu untuk mneyampaikan pesan
}

Seperti yang peneliti paparkan di atas sebelumnya, bahwa mantra pertanian pada masyarakat Paser di desa Baras Jiring sangat beragam, ada yang pendek, pertengahan dan panjang. Menurut narasumber yang peneliti wawancara (Narasumber: Bapak Harpansyah) mengatakan bahwa sengaja kata-katanya dibuat seperti itu dengan tujuan agar mantranya cepat dihapal dan dipahami.

Bait dalam mantra itu kebanyakan tidak beraturan karena mantra pada masyarakat Paser di desa Baras Jiring tidak begitu memperhatikan nilai struktur suatu mantra. Mantra di desa Baras Jiring lebih memfokuskan pada isi atau makna hakiki terciptanya mantra tersebut yakni sebagai alat atau media khusus untuk berdoa atau meminta restu Tuhan atas hajatan niatnya.

\section{Diksi Mantra}

Diksi merupakan pilihan kata yang dominan dan selalu mengikuti mantra tersebut selain dari kata pembuka dan penutup. ede iko mana kamurio lonsa ini aku membuang naas tom ban jiang ontun puli sala dion dengan beberapa obat (padi) ede iko mana bubuk bua bukon ini aku membuang bubuk (buah yang tidak jadi)

mana jawas bua ore membuang kesialan buah yg kecil yang tidak jadi

selanu bung bua latu belo keo kendulu utok belo keo beleleng wae belo keo layong molo belo keo mekom malom seluruh buah-buahan yang jatuh tidak ada sakit kepala tidak ada pusing muka/wajah tidak ada panas (matahari) siang tidak ada demam pada malam hari

apan roni damurowe supaya dingin perasaan apan rempai damuria supaya enak perasaan apan rempai ngarumpayon supaya sehat selalu apan tonga lio lonik supaya badan bersih

Kata yang dominan atau sering kita temukan pada setiap mantra adalah kata (iko) pada bait mantra ksatu dan kedua, (belo) 
terdapat pada bait mantra yang ketiga dan keempat. Pada mantra di atas mengandung suatu penegasan untuk maksud atau harapan apa yang diminta terkabulkan.

\section{SIMPULAN}

Berdasarkan uraian pada pembahasan di atas bahwa mantra Tipong Tawar dalam ritual pertanian Dayak Paser terdapat bentuk dan struktur yang sama dengan struktur puisi karena mantra juga merupakan puisi lama dalam genre sastra. Adapun bentuk dan struktur teks mantra Tipong Tawar meliputi; tema, formula bunyi (rima dan irama), bait, baris, dan diksi. Dapat disimpulkan bahwa terkait dengan struktur pada teks mantra Tipong Tawar berdasarkan pada tema, rima, irama, bait, baris, dan diksi memang berbeda dengan struktur pada puisi pada umumnya, terutama pada diksi sebuah teks mantra. Diksi pada teks mantra menggunakan bahasa daerah yang tidak semua arti dalam bahasa Indonesia tidak dapat dimaknai secara harafiah. Hal ini yang membedakan mengenai diksi teks mantra dan diksi puisi pada umumnya.

\section{DAFTAR PUSTAKA}

Aminuddin. 2011. Pengantar Apresiasi Karya Sastra. Bandung: Sinar Baru algesindo.

Amir, A. 2013. Sastra Lisan Indonesia. Yogyakarta: Penerbit Andi.

Bety, Nur. Dkk. 2014. Morfologi Bahasa Paser. Samarinda: Kantor Bahasa provinsi Kalimantan Timur.

Djamaris, Edwar. 1990. Menggali Khasanah Sastra melayu Klasik. Jakarta: Balai Pustaka.

Effendi, Rustam. 2011. Sastra Banjar. Banjarbaru: Cipta Cendekia.

Endraswara, Suwardi. 2009. Metodologi Penelitian Folklor: Konsep, Teori, dan Aplikasi. Yogyakarta: Media Pressindo.
Hoed, B.H. 2011. Semiotik dan Dinamika Sosial Budaya. Jakarta: Komunitas Bambu.

Hutomo, Suripan Sadi. 1991. Mutiara Yang Terlupakan. Surabaya: HISKI Jawa Timur.

Hymes, Dell. 1974. Verbal Art as Performance. Terjemahan dari Bauman, Richard (eds). Texas: University of Texas.

Rusbiyantoro, Wenni. 2014. Kamus Bahasa Paser-Bahasa Indonesia. Samarinda: Kantor Bahasa Provinsi Kalimantan Timur.

Tjahjono, Tengsoe. 1988. Teori Sastra Indonesia Pengantar dan Apresiasi. Flores: Nusa Indah. 